\title{
A Simple Process to Fabricate Self-Aligned, High-Performance Torsional Microscanners; Demonstrated Use in a Two-Dimensional Scanner
}

\author{
H. Choo, D. Garmire, J. Demmel, and R. S. Muller \\ Berkeley Sensor \& Actuator Center (BSAC) \\ University of California at Berkeley
}

Using a new, simple, CMOS-compatible process carried out on SOI wafers, we have built high-performance torsional microscanners having vertically offset interdigitated-comb actuators. Our microscanner-fabrication process requires three photolithography masks: two to form the front-side microscanner structures and a third to define the backside openings (Figure 1). Both moving and fixed combs are fabricated in the same device layer $(30 \mu \mathrm{m}$ in thickness), and the offset combs are created by reducing the thickness of the fixed combs, but not that of the moving combs. Our process begins by removing the $1-\mu \mathrm{m}$ thick thermal oxide selectively to open rectangular windows at locations where the fixed combs are to be defined (Figure 1-1). In the following step, both fixed- and moving-comb sets are defined simultaneously with a single photolith $\bullet$ graphy mask; this is followed by DRIE-etch (Figure 1-2 \& 1-3). We then perform a timed-etch in the DRIE-etcher to obtain the desired vertical thickness for the fixed combs (Figure 15) without affecting the moving combs. The minimum gap between comb fingers can be as small as twice the alignment accuracy of the photolithography process, which is $\leq 0.4 \mu \mathrm{m}$ for state-of-the-art photolithography steppers. The uniformity of the offset heights by the timed-etch process depends on the performance of the DRIE machine. Using our STS etcher, we have been able to keep the overall variation in offset heights across the 4-inch wafer below $1.02 \%(\leq 0.15-\mu \mathrm{m})$ of the average value $(15 \mu \mathrm{m})$ (Table 1$)$. This value is smaller than the typical thickness fluctuations $(0.5-2 \mu \mathrm{m})$ found in the device layers of SOI wafers. The simplicity of this fabrication method and its straightforward use of well-established IC-processing tools, provide excellent uniformity, performance, and reliability in the combdrive characteristics as well as excellent yields. We have designed and built microscanners having torsional resonant frequencies between 0.8 and $16.4 \mathrm{kHz}$ and maximum optical-scanning angles between 8 and $23.3^{\circ}$ with actuation

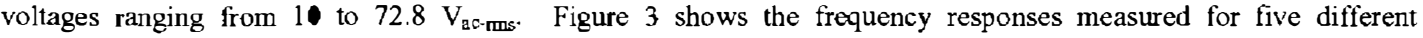
microscanners. We have made two separate fabrication runs and achieved yields of operating devices better than $75 \%$. Damages to microscanners mostly occurred during the HF-release/rinsing/critical-point-drying steps as a consequence of rough handling.

We consider these microscanners as especially well adapted for applications to refractive laser surgery of ocular corneas where small spot size and high scan speeds are important assets. To demonstrate this application, we assembled a two-dimensional scanning system by orienting two identical microscanners at right angles to one another (Mirror \#3 in Figure 3, mirror diameter $=1 \mathrm{~mm}$, resonant frequency $=6.01 \mathrm{kHz}$ ) and scanned a pulsed laser beam ( $670 \mathrm{~nm}$ wavelength). The cross-coupled scanners were driven by two $6.01 \mathrm{kHz}$ sine waves that were $90^{\circ}$ out of phase, producing circular patterns having radii fixed by the amplitude of the driving voltage. The laser spots forming the

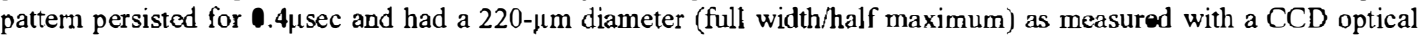
sensor. The CCD sensor, used in place of an ocular cornea, allows us to assess performance of the system. Refractive laser surgery is a cumulative ablation process [1] so to mimic the real process, we capture the scanning pattern at each CCD frame and then sum the intensity profiles which are proportional to the final ablation pattern. The usual period of time for optical laser surgery is shorter than 20 minutes so we measured the repeatability and stability of our system over a period of 30 minutes (Table II)

Our system shows excellent repeatability in pulse position (standard deviation less than $1.56 \mu \mathrm{m}$ ) as well as in pulse diameter (standard deviation less than $0.68 \mu \mathrm{m}$ ) around the ablation zone (Table II). To demonstrate the versatility of our area scanner, we have emulated a small pattern from the surface topography found on a US Roosevelt dime (Figure 4) and have built up an ablation pattern over a 40-minute interval (Figure 5). The resultant pattern compares favorably with similar emulations of such ablation patterns in the literature [2].

The high performance and excellent yield of our self-aligned vertically offset scanners result from our improved and simplified fabrication technology as compared to technologies reported in previous research. Fabrication challenges encountered in this earlier work include: (a) the nead for critical-alignment steps in a two-wafer process [3]; (b) a need to control and replicate the properties of materials like photoresist or bi-morph layers when they are used for hinges [4]; (c) a need for post-process-annealing in a high-temperature furnace following the hand assembly of tid and device chips [5]; (d) a need to deposit multiple-masking layers (composed of silicon dioxide and silicon nitride) to create offset combs [6].

References

[1] J. F. Bille, C. F. H. Hamer, and F. H. Loesel, "Aberration-Free Refractive Surgery," 2nd Edition, Springer-Verlag, 2004, Chap.10, New York, USA [2] op. cit. Chap. 10, page 82

[3]. R. A. Conant, J. T. Nee, K. Y. Lau. and R. S. Muller, "A flat high-frequency scanning micromirror," Hilton Head Solid-State Sensor and Actuator Workshop 2000, pp.6-9, Transducer Research Foundation, Cleveland, OH, USA

[4]. P. R. Patterson, D. Hah, H. Nguyen, H. Toshiyoshi, R. Chao, and M. C. Wu, "A scanning micromirror with angular comb drive actuation.". Interantional Conference on Micro Electro Mechanical Systems 2002, pp.544-7, Las Vegas, NV, USA

[S] J. Kim, H. Choo, L. Lin, and R. S. Muller, "Microfabricated torsional actuator using self-aligned plastic defomation," IEEE Transducers 2003, pp115-118, Boston, MA, USA

[6] D. T. McCormick and N. C. Tien. "Multiple Layer Asymmetric Vertical Comb-Drive Actuated Trussed Scanning Mirrors," IEEE/LE Intemational Conference on Optical MEMS 2003, pp.12-13, Waikoloa, Ha waii, USA 


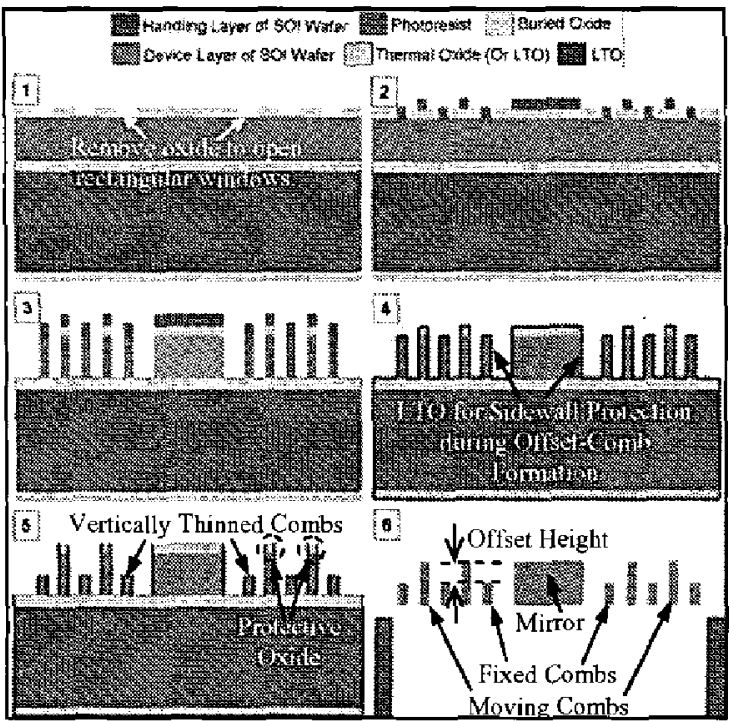

Figure 1 Fabrication Process: The left column shows top views while the right column shows cross-sectional views along the dotted lines. 1. Grow $\bullet .5-\mu \mathrm{m}$ thermal or lowtemperature oxide (LTO) for completely CMOS-compatible process. Using the photolitho-graphy mask \#1, pattern and remove the thermal oxide selectively where fixed combs will be later fabricated; 2. Using mask \#2, create patterns of microscanners including moving \& fixed combs, flexures, and mirrors; 3. Use deep-reactive-ion-etch (DRIE) to define the microscanners in the device layer; 4 . Remove the photoresist layer and deposit a very thin layer $(\sim .2 \mu \mathrm{m})$ of LTO; 5 . Use timed-anisotropic-plasma etch to remove $0.2-\mu \mathrm{m}$ thick LT from the top-facing surfaces. Then use timed-anisotropic or isotropic silicon-etch to create a set of vertically thinned combs; and 6. Using mask \#3, pattern and open the backside of the microscanners. Release the devices in $\mathrm{HF}$.

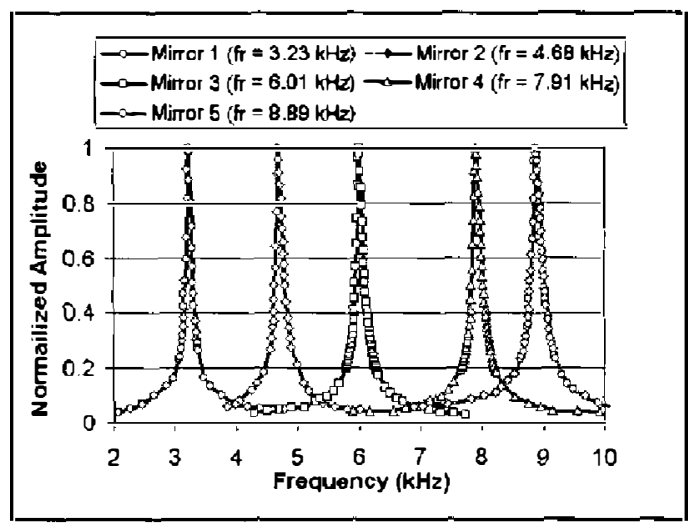

Figure 3 Frequency response of five different microscanners: The amplitude of each microscanner is normalized with respect to its own peak amplitude.

\begin{tabular}{|c|c|c|c|c|}
\hline Center & Left & Right & Top & Bottom \\
\hline $1.53 \%$ & $-1.38 \%$ & $\mathbf{0 . 1 3} \%$ & $\mathbf{0 . 9 0} \%$ & $\mathbf{- 0 . 2 8} \%$ \\
\hline
\end{tabular}

Table I Deviations from the average offset-height $(15 \mu \mathrm{m})$ across the 4-inch wafer: The 'Bottom' region corresponds to the wafer's flat side. (Overall non-uniformity $=1.02 \%$ )

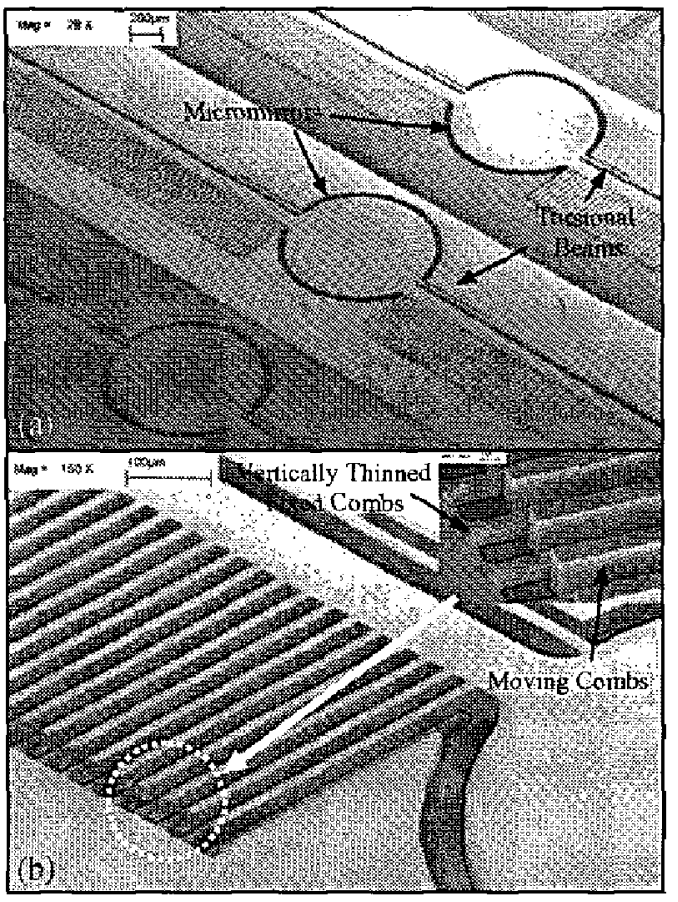

Figure 2 SEM pictures of microscanners (device layer thickness $=30 \mu \mathrm{m}$ ): The inset in the picture (b) clearly shows the formation of offset combs. (The gap between combs is $5 \mu \mathrm{m}$ wide. The offset height is $15 \mu \mathrm{m}$.)

Ablation Circles
(Max. Diameter = 5 mm)
\begin{tabular}{l|c|c|c|c|c|}
\hline Location & 1 & 2 & 3 & 4 & 5 \\
\hline Centroids & $0.06 \mu \mathrm{m}$ & $0.49 \mu \mathrm{m}$ & $0.55 \mu \mathrm{m}$ & $0.47 \mu \mathrm{m}$ & $0.56 \mu \mathrm{m}$ \\
\hline Diameters & $0.58 \mu \mathrm{m}$ & $0.64 \mu \mathrm{m}$ & $0.68 \mu \mathrm{m}$ & $0.63 \mu \mathrm{m}$ & $0.60 \mu \mathrm{m}$ \\
\hline
\end{tabular}

Table II Repeatability of the ablation-pulse locations (centroids, standard deviations) and stability of the pulse diameters at five different locations in the circular ablation zone

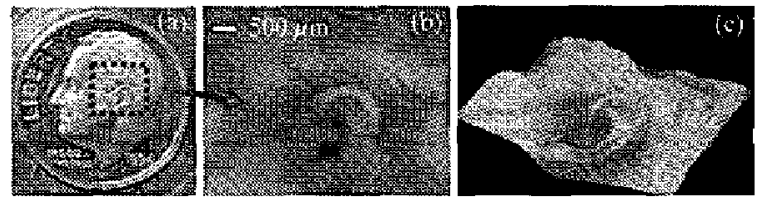

Figure 4 (a) Picture of a US dime, (b) gray-scale image and (c) 3-dimensional profile of the region of interest indicated by the dotted circle (measurements done by using WYKO NT 3300)
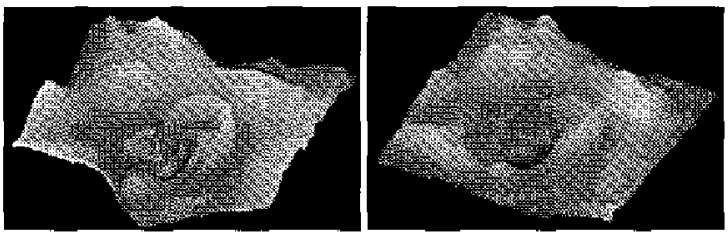

Figure 5 Left: Original 3-D surface profile of a US dime, Right: 3-D diagram of small-spot ablation of the dime's surface using our microscanners (peak-to-valley height difference $\cong 93 \mu \mathrm{m}$ ) 